\title{
Electrochemical Behavior of Iron Electrodes in Alkaline Solutions I. Effect of Electrolyte Concentration
}

\author{
Yoshifumi YAMAMOTO
}

Received August 7, 1991; Accepted March 18, 1992

\begin{abstract}
The anodic and the cathodic polarization behaviors of the iron electrodes in aqueous $K O H$ solutions were investigated by cyclic voltammetry. The maximum current values for the main redox peaks ( the third oxidation peak: about $-0.5 \mathrm{~V}$ and the first reduction peak: a jout $-0.95 \mathrm{~V}$ ) were obtained at about $1 \mathrm{M} \mathrm{KOH}$ solution. But, these current values decreased at high concentrations. In opposition, the current values of the first and second oxidation peaks and the second reduction peak increased slightly at high concentrations. The first and second oxidation peaks are related to the second reduction peak, the third oxidation peak has a relation to the first reduction peak.
\end{abstract}

\section{INTRODUCTION}

The electrochemical behaviors of the iron electrodes in alkaline solutions have historically been investigated principally by L.ojefors, A.J.Arvia et al. using a cyclic voltammetry under various experimental conditions.

For example, there were studies concerning a slow potentiodynamic method of porous sintered iron electrodes ${ }^{1}$ ), concerning the reactions of the iron electrodes based on $\mathrm{X}$-ray diffraction ${ }^{2)}$ and scanning electron microscopy ${ }^{3)}$, concerning the effects of hydrogen absorption-desorption on the electrolytic activation of the sinteredtype iron electrodes 4 ), concerning the temperature dependence of the iron electrodes ${ }^{5)}$, concerning the electrochemical and ellipsometric responses of the iron electrodes ${ }^{6-8)}$, concerning the elucidation of the iron film formed after oxidationreduction cycles by Raman spectroscopy $9-$ 11).

Recently, it has been pointed out that cadmium substances used as a negative

Department of Chemistry, Faculty of Science and Engineering, Ritsumeikan University (Tojiin-kitamachi 56-1, Kita-ku, Kyoto 603 , japan)

Key Words: Iron electrode, Electrolyte concentrations, Cyclic voltammetry. electrode of nickel-cadmium alkaline battery are harmful to human beings. Thereupon, iron can be used as one of the substitutes for active materials.

In this paper the electrochemical behavfors of the iron electrodes in alkaline solutions were investigated. Passably low $(0.01-1 \mathrm{M})$ or the limited concentrations of alkaline solutions have been used in most of above mentioned references. But, in a practical battery, it is impossible to keep an alkaline concentration constant because the concentration is changed under various conditions. The study concerning the adaptability of the electrolyte concentration in a practical. stage is a very important matter as the problem against the storage as well as the effectiveness of the active materials of a battery under the various electrolyte concentrations. So, the purpose of this work is to elucidate the influence of the electrolyte concentration on the behaviors of oxidation and reduction peaks in the cyclic voltammograms at the iron electrodes. Measurements were performed in aqueous $\mathrm{KOH}$ solutions at $298.15 \mathrm{~K}$ since the most favorable discharge curves and cyclic voltammograms were obtained at $298.15 \mathrm{~K} \mathrm{1,3,5)}$. Moreover, the mild steel plate had been chosen as the most simple system in order to avoid the complexity at a porous sintered iron electrode. 


\section{EXPKRTMIRTITAI,}

The working electrode was a mild steel plate of $1 \mathrm{~cm}^{2}$ (thickness: $1.0 \mathrm{~mm}$, the result of the other elemental. analyris: $c: 0.051$, S1: $0.01, \mathrm{Mn}: 0.33, \mathrm{P}: 0.06$, s:0.018) polished with abrasive paper, ref. 1000 and sealed with epoxy resin on its back side, after the annealing in a hydrogen stream for one hour at $923.15 \mathrm{~K}$. The counter electrode was a platinum plate of $2.25 \mathrm{~cm}^{2}$. The electrode potential was measured against $\mathrm{Hg} / \mathrm{HgO} / 4.7 \mathrm{M}-\mathrm{KOH}$ relierence electrode. Aqueous $1.0 \mathrm{M}, 3.011,4.7 \mathrm{M}, 6.0 \mathrm{M}$, and $8.0 \mathrm{M} \mathrm{KOH}$ solutions were used as an electrolyte. The cyclic voltammograms were obtained at a sweeping rate of $41.7 \mathrm{mVs}^{-1}$ by sweeping the potential cathodically from $+0.60 \mathrm{~V}$ to about $-1.30 \mathrm{~V}$ (the evolution potential of hydrogen) and reversed anodically up to the starting potential by posturating charge discharge cycles. The experiments were carried out in an H-type glass cell at 298.15K. Prior to all measurements the electrolytes were degassed with nitrogen for a quarter of an hour in order to eliminate dissolved oxygen, and the electrodes were reduced for a quarter of an hour at the potential in a region of hydrogen evolution.

\section{RESULTS and DISCUSSIOK}

In Figs. 1 and 2, the characteristic behaviors of cathodic and anodic peaks for the iron electrode were shown against the concentration changes of aqueous potassium hydroxide solutions. First, in the cyclic voltammogram (solid line) of Fig.1 in the $1.0 \mathrm{MOH}$ solution, a very large reduction peak at the potential of about $-0.95 \mathrm{~V}$ and a very small reduction peak at about $-1.10 \mathrm{~V}$ were observed in a way of cathodic sweep from $+0.60 \mathrm{~V}$. While, in a way of anodic sweep from the potential of hydrogen evolution, a very large oxidation peak at about $-0.50 \mathrm{~V}$ was recognized.

Fundamentally similar behaviors to the curve in $1.0 \mathrm{M}$ KOH solution of Fig. 1 were also obtained for $3.0 \mathrm{M}$ and $4.7 \mathrm{M} \mathrm{KOH}$ solutions, and in Fig.2. But, it was recognized from these results that especially, a very large oxidation peak at about $-0.50 \mathrm{~V}$ (peak (III)) and a very large reduction peak at about $-0.95 \mathrm{~V}$ (peak (IV)) decreased

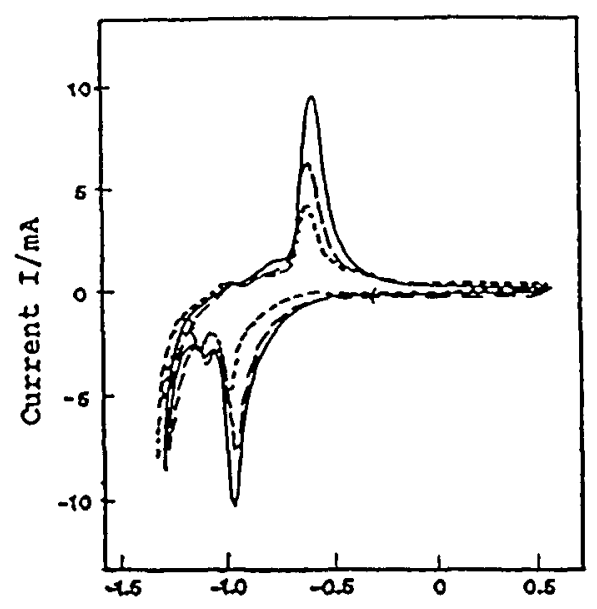

potentlal E/V $85 \mathrm{Bg} / \mathrm{BgO} / 4.7 \mathrm{M}$ KOR

Fig. 1 Cyclic voltammograms for the iron electrodes. Sweep rate is $41.7 \mathrm{mVs}^{-1}$.

- : In 1.0M KOH solution at the 30 th cycle

- : In $3.0 \mathrm{M} \mathrm{KOH} \mathrm{solution} \mathrm{at} \mathrm{the} 15 \mathrm{th}$ cycle

--- : In $4.7 \mathrm{M} \mathrm{KOH}$ solution at the 15 th cycle

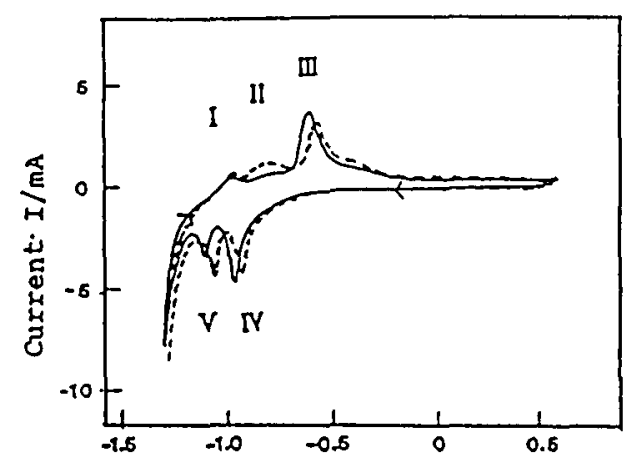

Potentlal E/V vs Hg/HgO/4.7M KOH Fig.2 Cyclic voltammograms for the iron electrodes. Sweep rate is $41.7 \mathrm{mVs}^{-1}$.

- : In $6.0 \mathrm{M} \mathrm{KOH}$ solution at the $15 \mathrm{th}$ cycle --- : In $8.0 \mathrm{M} \mathrm{KOH}$ solution at the 30 th cycle

gradually in accordance with the increase in the concentration of potassium hydrox1de, whereas a small reduction peak at about $-1.10 \mathrm{~V}$ (peak (V)) increased in a region of high concentration of $\mathrm{KOH}$, as observed clearly in $8.0 \mathrm{M} \mathrm{KOH}$ solution in Fig. 2. The maximum current values were obtained in $1.0 \mathrm{M} \mathrm{KOH}$ solution for both the oxidation $(-0.50 \mathrm{~V})$ and reduction $(-0.95 \mathrm{~V})$ process. Each curve of the cyclic voltam- 
mograms in Figs. 1 and 2 was the ones which indicated the highest current value among of 1 to 30 cycles. In connection with this selection, in fact, each peak of these electrodes in $3.0 \mathrm{M}, 4.7 \mathrm{M}$, and $6.0 \mathrm{M} \mathrm{KOH}$ solutions increased up to about 15 cycles, but in the later cycles the ones indicated the tendency to decrease slightly.

In $\mathrm{F} 1 \mathrm{~g} .3$ wave-form analysis of each peak was carried out by shifting the reversing potential to the direction of a noble potential with each $0.1 \mathrm{~V}$. The starting potential is the potential of hydrogen evolution, and the cyclic voltammograms were traced anodically up to the reversing potential and were reversed down cathodically to starting potential.

From these results, it was recognized that peak (V) is the cathodic counterpart of both anodic peaks (I) and (II), and that peak (IV) is the cathodic counterpart of anodic peak (III). Both peaks (I) and (II) therefore result in a single reduction process at peak ( $V$ ).

The electrochemical reactions related to main five redox peaks have been considered by some authors as the following equations $2,3,9-11$ ).

The first charge transfer process, which gives rise to peaks (I),(II) is the oxidation of $\mathrm{Fe}$ to $\mathrm{Fe}(\mathrm{OH})_{2}$ as the following equation, and peak (V) is the reverse reaction.

$$
\mathrm{Fe}+2 \mathrm{OH}^{-} \rightleftharpoons \mathrm{Fe}(\mathrm{OH})_{2}+2 \mathrm{e}^{-}
$$

The second charge transfer process results in peaks (III) and (IV) as follows.

$$
\mathrm{Fe}(\mathrm{OH})_{2} \rightleftharpoons \mathrm{FeOOH}+\mathrm{H}^{+}+\mathrm{e}^{-}
$$

Through a series of these behaviors in the various concentration of $\mathrm{KOH}$ solution, it was generally recognized that both the main peaks (III) and (IV) decreased gradually with the incresse in the concentration of KOH solution. From these phenomena, it may probably be conjectured that the decomposition of $\mathrm{Fe}(\mathrm{OH})_{2}$ to $\mathrm{FeOOH}$ written as the equation (2) was difficult by the incresse of the electrolyte concentration, and or,there was a cause against the mass transport phenomenon (a diffusion velocity

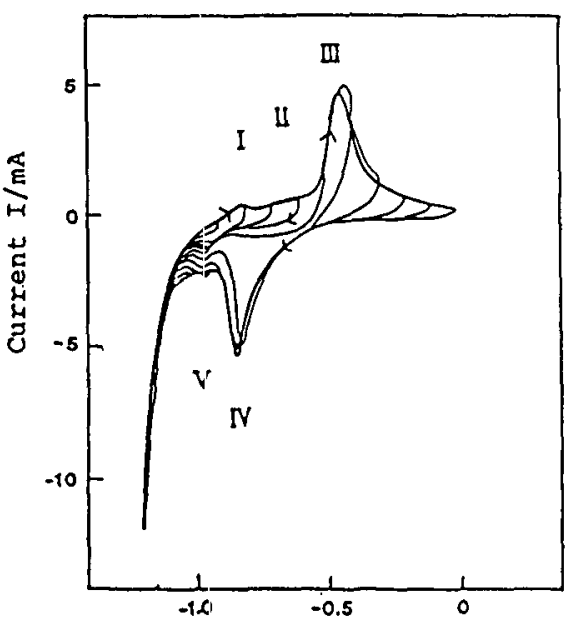

Potentlal $\mathrm{E} / \mathrm{V}$ Vs $\mathrm{hg} / \mathrm{HgO} / 4.7 \mathrm{M} \mathrm{KOH}$

Fig. 3 Cyclic voltamograms obtained by shifting the reverging potential to the direction of a noble potential from the potential of hydrogen evolution with each $0.1 \mathrm{~V}$ after the electrode had been cycled between $+0.60 \rightleftharpoons-1.30 \mathrm{~V}$ for 50 cycles in $1.0 \mathrm{M}$ KOH solution. Sweep rate is $41.7 \mathrm{mVs}^{-1}$.

of $\mathrm{H}^{+}$ion) by the increase of the electrolyte viscosity. On the other hand, the increase of the peak ( $V$ ) was closely related to the increase in $\mathrm{OH}^{-}$concentration.

This should be ascribed to the increase in the amount of $\mathrm{Fe}(\mathrm{OH})_{2}$ produced during the anodic sweep (peak (I),(II)), since the equilibrium of the equation (1) shifted toward righthand side.

For reference, the surface observations of the iron electrodes were carried out by scanning electron microscopy as shown in Figs. 4 and 5 thout samples after anodic sweeps. The electrode in the $1.0 \mathrm{M} \mathrm{KOH}$ solution which shows the largest current values, and another electrode in the $6.0 \mathrm{M}$ $\mathrm{KOH}$ solution which shows the smallest current values were examined.

As seen in Figs. 4 and 5, two electrodes showed the morphologic difference.

\section{COMGLUSIONS}

In this paper: the electrochemical redox beheviors of the iron electrodes in aqueous potassium hydroxide solutions were investi- 


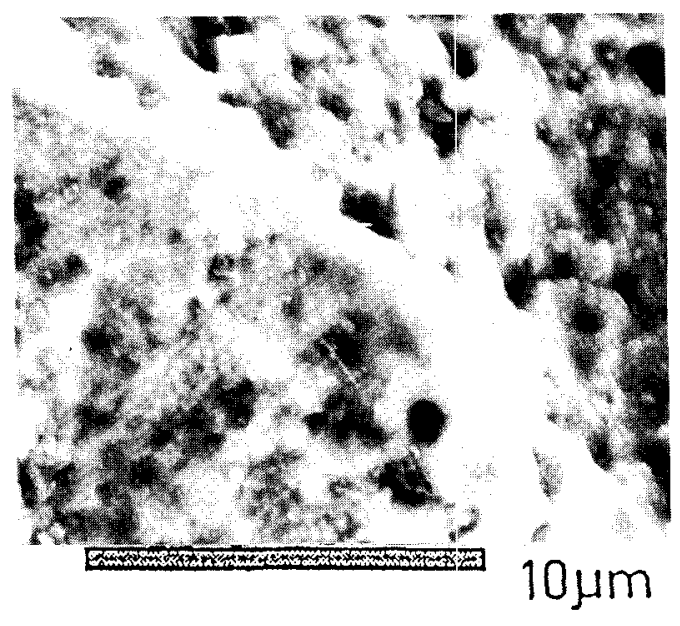

F1g. 4 SEM photograph of oxidized active materials on surface of an iron electrode after anodic sweep in $1.0 \mathrm{M} \mathrm{KOH} \mathrm{solution.}$

gated using potentiostatt.c method and scanning electron microscopy. The purpose was to elucidate the characteristic of each redox peak for the varlous concentrations of the electrolytes, and the correlation among these peaks of Iron electrode.

The main results are as follows.

(1) The maximum current values for the main redox peaks were obtained at about $1 \mathrm{M}$ KOH solution.

(2) This current values decreased at high concentrations of an electrolyte solution.

(3) The first (I) and second (II) oxidation peaks have relation to the second (V) reduction peak, the third (III) oxidation peak has relation to the first (IV) reduction peak.

(4) Different morphologies were recognized by SEM for the electrodes oxidized in $1.0 \mathrm{M}$ and $6.0 \mathrm{M} \mathrm{KOH} \mathrm{solutions.}$

(5) The second reduction peak (V) appreclably increased in about $8.0 \mathrm{M} \mathrm{KOH} \mathrm{solu-}$ tion.

\section{REPEREHCES}

1) B.Andersson and L.Ojefors, J. Electrochem. Soc., 123, 824 (1976).

2) H.G.Silver and E.Lekas,

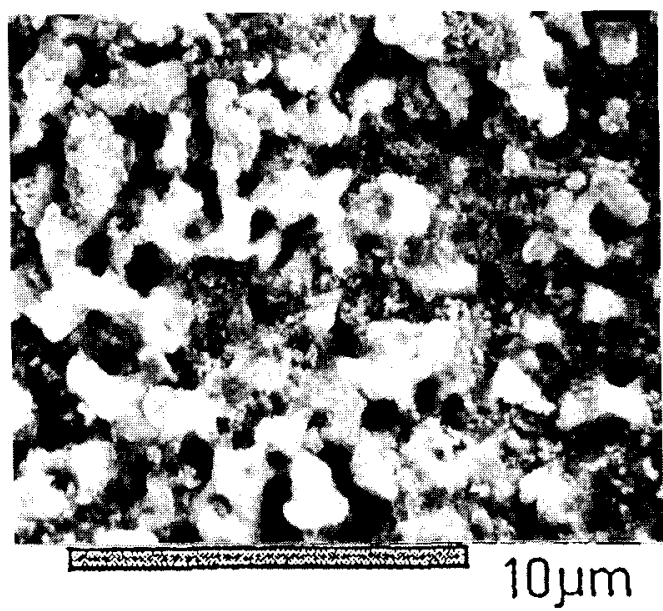

E1B. 5 SEM photograph of oxidized active materials on surface of an iron electrode after anodic sweep in $6.0 \mathrm{M} \mathrm{KOH}$ solution.

J. Electrochem. Soc., 117, 5 (1970).

3) L.ojefors,

J. Electrochem. Soc., 123, 1691 (1976).

4) D.Yamashite, Y.Yamamoto, K.Masuse and H.Yoвida, Nippon Kagaku Kalshi, 525 (1978).

5) A.Wleckowsk1, E.Gholl and H.H.Le, J. Electrochem. Soc., 131, 2024 (1984).

6) O.A.Albani, J.0.Zerbino, J.R.Vilche and A.J.Arvia, Electrochimica Acta, 31, 1403 (1986).

7) S.Juanto, J.0.Zerbino, M.I.Miguez, J.R.V1lche and A.J.Arvia, Electrochimica Acta, 32, 1743 (1987).

8) O.A.Alban1, L.M.Gassa, J.O.Zerbino, J.R.VIlche and A.J.Arvia, Electrochiofca Acta, 35, 1437 (1990).

9) M.Froelicher, A.H.Goff, C.Pallota, R. Dupeyrat and M.Mason, in Passivity of Metals and Semiconductors

(Edited by M.Froment), pp.101-105, Elsevier, Amsterdam (1983).

10) J.Dunnwald, R.Losy and A.Otto, in Passivity of Metals and Semiconductors (Edited by M.Froment), pp.107-112, Elsevier, Amsterdam (1983).

11) J.Dunnwald and A.Otto, Z.Anal.Chem.,319, 738 (1984). 